\title{
Integrating Games into Picture Books to Facili- tate the Development of Social Emotions in Pre- schoolers: An Empirical Study on the Positive Effects of Game-Combined Guided Reading of Picture Books on Social Emotional Development in Preschoolers
}

\author{
Juzhe Xi, Wenying Zhou, Zhihong Zuo \\ East China Normal University, Shanghai 200062, China
}

\begin{abstract}
This 6-week experimental study aimed to examine the effects of game-combined guided reading of picture books on children's social emotional development. Pre- and post-test design was used among a sample of 81 children and their parents from 3 senior classes in a Shanghai public kindergarten. The participants were divided into five groups: guided reading group, self-reading group, reading-withlistening group, and two control groups. In both pre- and post-tests, children's parents were administered measurement "The Scale of School Readiness in Emotional and Social Areas for Children". The guided reading group was asked to read picture books by following the instructions, the self-reading group read the picture books by themselves, while in the reading-with-listening group, the investigator read the stories out loud to the children and pointed to the text. The two control groups did not read picture books, and the second control group was mainly used to investigate the effects of the pre-test. The results indicated that all types of reading had significant effects on the improvement of children's social-emotional development with difference across the groups. The game-combined guided reading had more significant effects on children's interpersonal relationships and self-awareness development than the other two reading styles, but the effect on children's moral development was at the statistically marginal level and was significantly higher in the other groups. Our data suggest that picture book reading is effective in promoting children's social-emotional development. Furthermore, game-combined guided reading is suitable for children's psychological characteristics, and has much greater promoting effects on their
\end{abstract}


$X i$, et al. Games Combined Picture Books and the Social Emotions in Preschoolers

social-emotional development. If adults could add mini games to the reading, it would enhance children's positive experience and contribute to their social-emotional development.

Best Evid Chin Edu 2019; 3(1):305-320.

Doi: 10.15354/bece.19.ar1076

Keywords: Game; Picture Books; Reading; Social Development, Social-Emotional Development; Kindergarten Senior Class

Correspondence to: Zhihong Zuo, Associate Professor, Department of Preschool Education, Faculty of Education, East China Normal University, China; Email: zuozhihong@126.com.

About the Author Juzhe Xi, Professor, Department of Applied Psychology, School of Psychology and Cognitive Science, East China Normal University, China; Email: jzxi@psy.ecnu.edu.cn.

Wenying Zhou, Graduate Student, Department of Applied Psychology, School of Psychology and Cognitive Science, East China Normal University, China; Email: ecnuzhouwenying@163.com.

Conflict of Interests: None. 
$\mathrm{A}$

S an important component of psychological development, social development has aroused increasing attention. Since early 1930s, Western scholars have begun to study social development in children that regarded children as active participants in social activities rather than passive socialized individuals. Freud's theory of personality, Vygotsky's cultural-historical psychology, and Meade's Cultural Determinism were considered the three most important theoretical bases of children's social development (Chen, 1994). Since the 1980s, the term 'social' has been recognized in preschool and school-aged education in China (Shi, 1994). From the mid-1980s, the focus of preschool education has shifted from intelligence development to children's overall development. Since the mid and late 1990s, quality-oriented education and the cultivation of children's sociality have been strongly promoted.

Social development is not only an important part of children's psychological development, but also the foundation of healthy personality and social adaptation ability. The Guidelines for Kindergarten Education (Trial Version) issued by the Ministry of Education of China in 2001 stated that the purpose of social development in preschool children is to build up their 'willingness to communicate, learn, cooperate and share, and compassion for others'. Social development can facilitate children's formation of multi-dimensional and multi-level psychological structure, shapes their personality structure of agreeableness and intelligence, and builds up their morals of gregariousness and harmony (Liu, 2010). Children with such social competence are likely to understand social norms, master life skills, manage interpersonal relationships and adapt to social life (Yang \& Wu, 2001). A nationwide survey showed that promoting children's social and emotional development helped reduce the occurrence of behavioral problems (Lian et al., 2008).

Emotion is one of the four most important factors in children's sociopsychological structure and a core field in their social development (Chen, 1994; Shaffer \& Kipp, 2013). Social-emotional development, as a critical component of children's social development, is particularly important to preschool children (Pahl, 2007). Socialemotional development refers to the generation of emotions with social significance in the process of interpersonal communication and social behavior feedback on the basis of primitive emotions (Meng, 1989). Children with high levels of social-emotional development tend to be more confident, have better peer relationships and more cooperative spirit, and be more capable of managing and regulating emotions, solving conflicts and promoting interpersonal communication and social adaptation (Cunningham, et al., 2009; Mandez, et al., 2002). In contrast, children who have difficulties in socialemotional development tend to demonstrate poor performance in school life, peer relationships and academic learning (Aviles, 2005; Harniss, 1999). The transition from kindergarten to elementary school is a crucial stage of overall development in preschool children. Therefore, this stage requires special attention (Chen, 2008). The main task of social development in preschool children is to have emotional interaction and maintain positive social interaction. It is imperative to prepare preschool children to have socialemotional development in accordance with the purpose of social development stated in 
the Guidelines for Kindergarten Education (Trial Version) so that the children may have a better transition from kindergarten to elementary school.

Picture books are suitable materials for preschool children. The effects of picture book reading on children's development have aroused great attention. High quality picture books do not only deliver knowledge, but also inspire courage, sow hope, and cultivate children's temperament (Geng, 2010). The results of previous empirical research suggested that picture books play a significant role in promoting children's social-emotional development. For example, picture book reading can effectively promote the development of children's social interaction and moderate their challenging behaviors (Zuo, et al. 2012). It promoted children's self-perception, interpersonal relationships and understanding of social regulations (Zhang \& Zeng, 2016). In addition, reading picture books could encourage pro-social behaviors and improved social adaptability in preschool children (Du, 2015; Yang, et al., 2014). The existing empirical studies on the use of picture books had provided enlightenment and directions for socialemotional development education in children (Liu, S., 2003; Xie, 2003).

In addition to picture book reading, playing games is also a crucial way to support children's social-emotional development (He \& Liu, 1999; Zhou, 1990). Vygotsky maintained that playing games is a purposeful and conscious social activity among children (Lv, 2006). For example, sports games can improve social interactions, help free children from self-centered traits, and cultivate positive emotions and healthy psychological quality (Yang, 2002). Role-playing games can reinforce pro-social behaviors, improve social cognition, and promote peer interaction and cooperation (Duan, 2010). Moreover, autonomous games can promote the development of social cognition, social emotions, social skills, social morality and self-awareness (Meng, 2014).

In summary, the combination of picture book reading with game playing in the kindergarten curriculum is a new and worthwhile topic. For example, Jiangsu Provincial Department of Education launched a Gamification Course program in 2014, aiming to guide kindergartens to set up correct views on children, games and curriculum (Cao, 2016). In Sun's (2017) study of early childhood reading in the context of gamification curriculum, picture book stories were put through into children's daily life in the form of games. The Picture Books Game Course was developed on the basis of the holistic function of picture book reading. Fei (2016) and Leng (2017) explored new ways of using picture books and new models of picture-book-based education so that the overall development in children could be promoted. Kindergarten teachers integrated performance games into activities of picture book reading to stimulate children's abilities to perform and comprehend reading materials. This method assumed that picture books are a critical carrier of children's experiencing of games (Peng, 2016). Fang (2012) maintained that picture books contain game elements in the perspectives of form, content and usage. Therefore, the combination of picture book reading with games can facilitate children's understanding better of the material (Guo, 2015). Previous study indicated that gamified electronic picture books which integrate the characteristics of games into learning materials can improve students' concentration and interest in learning (Chen, 2017). In spite of the existing literature that suggested many benefits of combin- 
ing picture book reading with games, concise and instructive curriculum frameworks for educators are rare. Such frameworks are crucial for educators to grasp the essentials quickly and generate an educational system which integrates games into picture book reading.

This study developed a mode of game-combined guided reading of picture books, which integrated picture book reading and games. During the reading process, thought provoking and guiding approaches were applied, different levels of questions were asked, and story related mini-games were designed. In the process of gamecombined guided reading of picture books, children's initiative was paid full respect. The investigators used different approaches to encourage the children to participate in discussions and used various methods to stimulate children's motivation. The goal was to help children to connect their existing life experiences and knowledge to the content of the story. Thought provoking questions were used to guide them to think, and to cultivate their skills of anticipation, hypothesizing, questioning, and reflection. Role-play, sports games and action mimicking were utilized to internalize and consolidate children's social-emotional knowledge, and to enhance their social-emotional skills. The purpose of this study is to examine whether this innovative reading method, in comparison to traditional methods of picture book reading (e.g., self-reading, reading-withlistening), could improve children's social-emotional development through participation and enriched experience of picture books.

\section{Methods}

\section{Sample}

A volunteer sample of 81 preschool children including 47 boys (58.02\%) and 34 girls $(41.98 \%)$, and their parents were the participants of this study. All the children were from a senior class of a public kindergarten in Shanghai where social-emotional development curriculum was not offered. All participants were under the 'equivalent conditions'. We herein define 'equivalent conditions' as no significant difference in age, physiological development, and parent-and-child shared reading (e.g., attitude, frequency and time). Prior to the experiment, all participants were randomly divided into five groups. An analysis of single factor ANOVA for social-emotional development was conducted with all five groups of participants. The results indicate that there were no significant differences in the first four groups of social-emotional scores $(F(3,63)=0.93$ $-2.44, \mathrm{p}>0.05)$. The fifth group did not participate in the pre-test. There were no significant differences in age among each group $(\mathrm{F}(4,76)=0.68, \mathrm{p}=0.957)$. As shown in the Table 1, there were no statistically significant differences in terms of gender in each group $\left(\chi^{2}(d f=4, N=47)=3.54, \mathrm{p}=0.473\right)$.

\section{Tools and Materials}

\section{Outlines for Game-Combined Guided Reading of Picture Books}


Table 1. Participants' Demographic Information.

\begin{tabular}{lllll}
\hline Group & Number & Boy $(\mathbf{n})$ & Girl (n) & $\begin{array}{l}\text { Average Age (mo) } \\
(\boldsymbol{M} \pm \boldsymbol{S} \boldsymbol{D})\end{array}$ \\
\hline Guided Reading Group & 19 & 13 & 6 & $73.00 \pm 3.39$ \\
\hline Self-Reading Group & 16 & 9 & 7 & $72.55 \pm 2.95$ \\
\hline Reading-with-Listening Group & 19 & 9 & 10 & $72.60 \pm 4.47$ \\
\hline Control Group 1 & 13 & 6 & 7 & $72.40 \pm 4.44$ \\
\hline Control Group 2 & 14 & 10 & 4 & $72.33 \pm 3.11$ \\
\hline
\end{tabular}

Note: The purpose of setting up Control Group 2 was to examine the effect of pretest.

The reading materials were selected from The Way I Feel series of picture book by Cornelia Maude Spelman. The author was a therapist with children and families before turning full-time to writing and art. The reading materials included seven common social-emotional themes for preschool children: happiness, feeling scared, sadness, jealousy, self-confidence, missing someone, and empathy (see Table 2).

\section{Measurement of Social-Emotional Development}

This study used Yang's (2015) "the Scale of School Readiness in Emotional and Social Areas for Children", which was developed on the basis of the Five-Domain Model of School Readiness, Child Behavior Checklist and Child Social Development Scale within the Chinese cultural context. From Yang's scale, 44 items were selected. The children's parents were asked to indicate their children's performance in the aspects of interpersonal relationships (e.g., taking the initiative to play games with others), morals (e.g., never destroying plants and flowers or harming small animals), and selfawareness (e.g., using appropriate approaches to realize personal wishes). Responses were on a five-point Likert-type scale ranging from 'completely disagree' to 'completely agree'. The internal consistency coefficients demonstrate satisfactory psychometric properties (interpersonal relationships ( $\alpha=0.881)$, morals $(\alpha=0.898)$, self-awareness $(\alpha=0.830)$ and overall $(\alpha=0.864)$ ).

\section{Procedure}

As shown in the Figure 1, this study included three stages: pre-test, experimental design implementation, and post-test. The pre-test was to understand participant children's conditions of emotional development, select appropriate picture books, and make reading plans. The pre- and post-test utilized the same measurement. A team of university students who had received standardized training in advance implemented the experiment. Only one chief investigator was in charge of all the experiments in all five groups. This was to minimize experimenter bias. The guided reading group was provided with instructions in reading the game-combined picture books. Children in the self-reading group read the materials by themselves. In the reading-with-listening group, the chief investigator pointed to the texts while reading the story out loud, and the participant 


\section{Table 2. Outlines for Game-Combined Guided Reading of Pic-} ture Books.

Guided

Reading of

Game

Combined

Picture

Books

\begin{tabular}{|c|c|c|}
\hline \multicolumn{2}{|l|}{ Introduction } & \multirow{2}{*}{$\begin{array}{l}\text { Themes } \\
\text { Appropriate Reading Age }\end{array}$} \\
\hline & & \\
\hline & & Story Topic \\
\hline \multirow{2}{*}{\multicolumn{2}{|c|}{ Picture Book Introduction }} & Cover \& Back Cover \\
\hline & & Front Lining \& Title Page \\
\hline \multirow[t]{10}{*}{ Guided Reading } & \multirow{6}{*}{$\begin{array}{l}\text { Appropriate } \\
\text { Guiding Behaviors }\end{array}$} & Thought Provoking Questions \\
\hline & & Guiding Questions \\
\hline & & Experience Sharing \\
\hline & & Mini Games \\
\hline & & Action Mimicking \\
\hline & & Role Play \\
\hline & \multirow{4}{*}{$\begin{array}{l}\text { Inappropriate } \\
\text { Guiding Behaviors }\end{array}$} & Assigned Reading Materials \\
\hline & & Distraction, Perfunctoriness \\
\hline & & Literacy \\
\hline & & Lecturing in the Process \\
\hline \multirow{4}{*}{\multicolumn{2}{|c|}{ Post Reading }} & Summary Sharing \\
\hline & & Craft Work \\
\hline & & Mini-Games \\
\hline & & Conclusion \\
\hline
\end{tabular}

children listened to the story. The two control groups did not read picture books, and the second control group was only used to examine the pre-test effects. Children in the three experimental groups read picture books twice a week, 15-20 minutes each time, for a period of 6 weeks according to the setting of each experimental group.

\section{Data Analysis and Results}

\section{Significance Tests on Children's Social-Emotional Developmental Changes in Each Group}

The data of post-test from control groups 1 and 2 were compared. The results showed that there was no significant difference between the two groups (ps >.410). This finding indicated that receiving pre-test did not have impact on the participants' post-test results. Therefore, possible interference of the pre-test on the experimental results could be excluded. As shown in the Table 3, the results of pre- and post-test comparisons showed 


\begin{tabular}{|c|c|c|c|c|}
\hline $\begin{array}{l}\text { Experimental } \\
\text { Groups }\end{array}$ & & $\begin{array}{l}\text { Interpersonal } \\
\text { Relationship }\end{array}$ & Moral & $\begin{array}{l}\text { Self } \\
\text { Awareness }\end{array}$ \\
\hline \multirow{2}{*}{$\begin{array}{l}\text { Guided Reading Group } \\
(n=19)\end{array}$} & Pre-test & $40.53 \pm 4.58$ & $45.95 \pm 3.29$ & $60.95 \pm 6.10$ \\
\hline & Post-test & $55.32 \pm 4.36$ & $57.26 \pm 4.72$ & $76.00 \pm 6.31$ \\
\hline \multirow{2}{*}{$\begin{array}{l}\text { Self-reading Group } \\
(n=16)\end{array}$} & Pre-test & $41.69 \pm 3.44$ & $44.06 \pm 4.12$ & $61.88 \pm 6.31$ \\
\hline & Post-test & $51.69 \pm 3.26$ & $52.81 \pm 4.22$ & $73.25 \pm 3.86$ \\
\hline \multirow{2}{*}{$\begin{array}{l}\text { Reading-with-Listening } \\
\text { Group }(n=19)\end{array}$} & Pre-test & $42.58 \pm 7.40$ & $46.89 \pm 2.81$ & $63.53 \pm 8.66$ \\
\hline & Post-test & $50.89 \pm 3.56$ & $54.58 \pm 4.21$ & $72.68 \pm 5.93$ \\
\hline \multirow{2}{*}{$\begin{array}{l}\text { Control Group } 1 \\
(n=13)\end{array}$} & Pre-test & $43.46 \pm 4.05$ & $46.46 \pm 2.44$ & $65.23 \pm 5.93$ \\
\hline & Post-test & $50.31 \pm 4.11$ & $54.54 \pm 4.03$ & $69.69 \pm 4.99$ \\
\hline
\end{tabular}

significant improvement in all three aspects of interpersonal relationships, moral, and self-awareness among the four groups of participants $(t=2.27-13.91, \mathrm{p}<.05)$.

\section{Significance Tests on Children's Social-Emotional Developmental Changes among Different Groups}

The above findings suggested that the four groups of participants who had shown no significant difference in the pre-test had developmental changes in social emotions after completing their respective picture book reading tasks. As shown in the Table 4, a repeated ANOVA on the scores of three social emotions (interpersonal relationships, moral and self-awareness) by 4 factors (four groups: guided reading group, self-reading group, reading-with-listening group, and control group 1) $\times 2$ stages (two stages: pretest and post-test) was conducted. This was to examine the effects of guided picture book reading. The results showed that in the aspect of interpersonal relationships, the interaction effects within and between subjects reached the level of statistical significance $\left(F(3,63)=5.61, p=0.002, \eta_{p}^{2}=0.211\right)$. In the aspect of moral, the interaction effects within and between subjects reached the marginal level of statistical significance $\left(F(3,63)=2.42, p=0.075<0.10, \eta_{p}^{2}=0.075\right)$. For self-awareness, the interaction effects within and between subjects reached the extreme level of statistical significance $(\mathrm{F}(3,63)$ $=6.28, \mathrm{p}=0.001, \eta_{\mathrm{p}}^{2}=0.230$ ).

As shown in the Figure 2, the mean deviation among the four groups in all three aspects (i.e., interpersonal relationships, moral, and self-awareness) was compared. It was found that the improvements within the guided reading group were especially significant, i.e., the scores in all three aspects were higher than that of the reading-withlistening group and the control group 1, and also significantly higher than that of the self-reading group in the aspect of interpersonal relationships $(\mathrm{p}<0.05)$.

Simple effects tests on all three aspects were conducted. As shown in the Table 5, the results indicated that participants' performance in the post-test were significantly different among groups in the aspects of interpersonal relationships and self-awareness 
Table 4. Effects of Changes in Children's Social-Emotional Within Subjects, Between Subjects and Interactive Effects of Within Subjects \& Between Subjects.

\begin{tabular}{lllll}
\hline $\begin{array}{l}\text { Source of } \\
\text { Variation }\end{array}$ & $\begin{array}{l}\text { Statistical } \\
\text { Indicators }\end{array}$ & $\begin{array}{l}\text { Interpersonal } \\
\text { Relationship }\end{array}$ & Moral & $\begin{array}{l}\text { Self } \\
\text { Awareness }\end{array}$ \\
\hline Within Subjects $\times$ & $F(3,63)$ & $5.61^{* *}$ & $2.42^{\dagger}$ & $6.28^{* \star}$ \\
Between Subjects & $p$ & 0.002 & 0.075 & 0.001 \\
\cline { 2 - 5 } & $\eta_{p}^{2}$ & 0.211 & 0.103 & 0.230 \\
\hline Within Subjects & $F(3,63)$ & $178.76^{\star \star *}$ & $258.97^{\star \star *}$ & $135.10^{\star \star *}$ \\
\cline { 2 - 5 } & $p$ & $<.001$ & $<.001$ & $<.001$ \\
\cline { 2 - 5 } & $\eta_{p}^{2}$ & 0.739 & 0.804 & 0.682 \\
\hline Between Subjects & $F(3,63)$ & 0.52 & $3.18^{*}$ & 0.13 \\
\cline { 2 - 5 } & $p$ & 0.674 & 0.030 & 0.941 \\
\cline { 2 - 5 } & $\eta^{2}$ & 0.024 & 0.132 & 0.006 \\
\hline Note: ${ }^{\dagger} p<0.10,{ }^{*} p<0.05,{ }^{* *} p<0.01,{ }^{* * *} p<0.001$. & & \\
\hline
\end{tabular}

Table 5. Group Differences and Repeat Measure of Simple Effects Tests.

\begin{tabular}{lllllll}
\hline Origins of Differences & \multicolumn{2}{l}{$\begin{array}{l}\text { Interpersonal } \\
\text { Relationships }\end{array}$} & Morals & \multicolumn{3}{c}{$\begin{array}{l}\text { Self } \\
\text { Awareness }\end{array}$} \\
\hline & $F$ & $\eta^{2} \mathrm{p}$ & $F$ & $\eta^{2} \mathrm{p}$ & $F$ & $\eta^{2} \mathrm{p}$ \\
\hline $\begin{array}{l}\text { Guided Reading Group } \times \text { pre- } \\
\text { test and post-test }\end{array}$ & $\begin{array}{l}113 . \\
89^{* * *}\end{array}$ & 0.644 & $120.11^{* * *}$ & 0.656 & $88.74^{* * *}$ & 0.585 \\
\hline $\begin{array}{l}\text { Self-Reading Group } \times \text { pre-test } \\
\text { and post-test }\end{array}$ & $43.85^{* * *}$ & 0.410 & $60.48^{* * *}$ & 0.490 & $42.67^{* * *}$ & 0.404 \\
\hline $\begin{array}{l}\text { Reading-with-Listening Group } \times \\
\text { pre-test and post-test }\end{array}$ & $36.01^{* * *}$ & 0.364 & $55.39^{* * *}$ & 0.468 & $32.84^{* * *}$ & 0.343 \\
\hline $\begin{array}{l}\text { Control group 1 } \times \text { pre-test and } \\
\text { post-test }\end{array}$ & $16.70^{* * *}$ & 0.210 & $41.87^{* * *}$ & 0.399 & $5.33^{*}$ & 0.078 \\
\hline $\begin{array}{l}\text { Differences within Group } \times \text { Pre- } \\
\text { Test }\end{array}$ & 0.93 & 0.042 & $2.44 \dagger$ & 0.104 & 1.14 & 0.052 \\
\hline $\begin{array}{l}\text { Differences within Group } \times \text { Post- } \\
\text { Test }\end{array}$ & $6.03^{* *}$ & 0.223 & $3.19^{*}$ & 0.132 & $3.20^{*}$ & 0.132 \\
\hline Note: ${ }^{\dagger} p<0.10,{ }^{*} p<0.05,{ }^{* *} p<0.01,{ }^{* * *} p<0.001$. & & & & \\
\hline
\end{tabular}




\section{Figure 1. Experiment Procedure.}

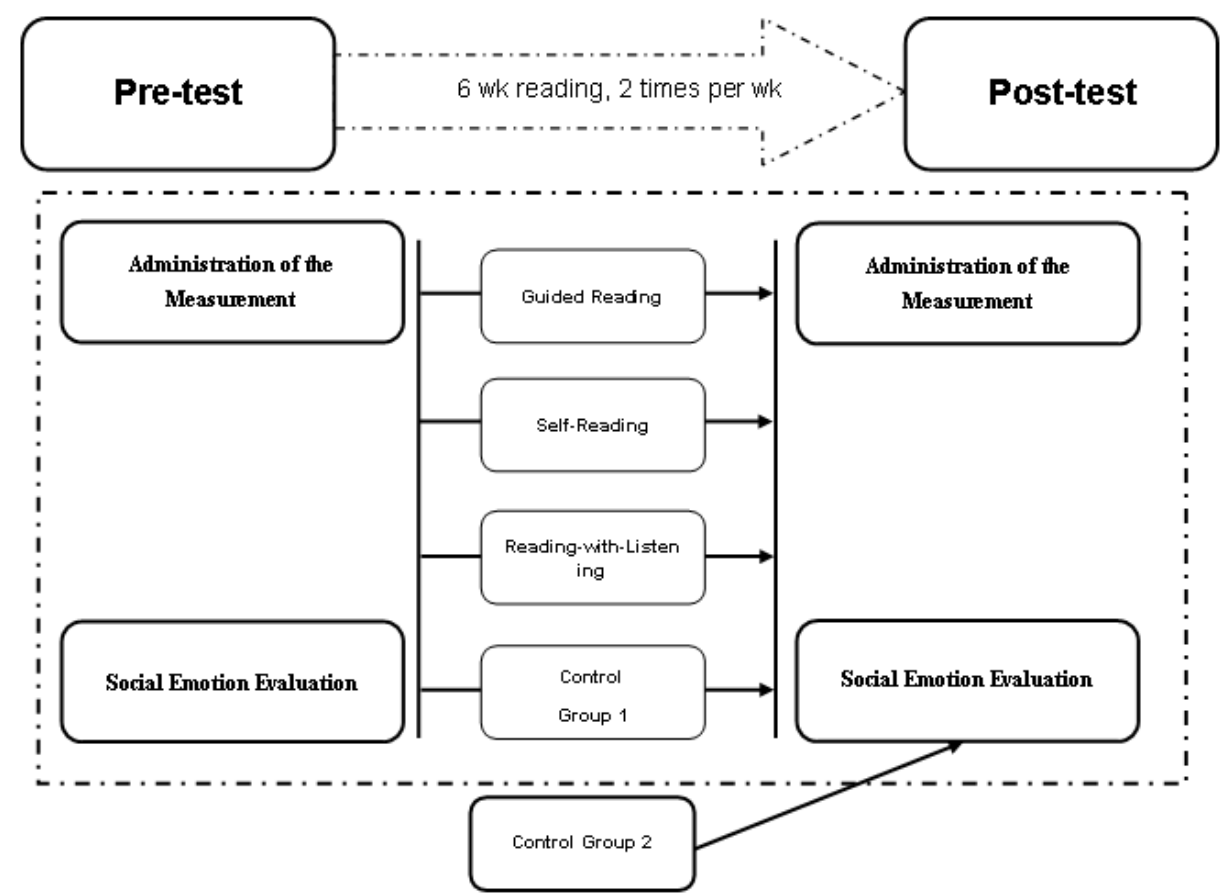

( $\mathrm{p}<0.001$ ). The results of comparisons among Tables 3 and 4 and Figure 2 indicate that there were more significant improvements in social-emotional development within the guided reading group than in other groups.

\section{Discussion}

\section{Game-Combined Guided Reading of Picture Books Is More Effective in Promoting Children's Social-Emotional Development}

As shown in the Figure 2, after the 6-week experiment, the social-emotional development levels in the entire participant children have been improved. The experiment began during the second semester in a kindergarten's senior class, where the courses and activities related to the transition from kindergarten to elementary school were conducted. The children in the control groups also had a significant improvement in their level of self-awareness as their age increased. The fastest development stage was 4-8 years old (Ran, 1994). All the participant children in this study were exactly on this stage. Therefore, their self-awareness was developing rapidly in a positive trend. The interaction within and between subjects (see Table 4) suggested that game-combined guided 


\section{Figure 2. Comparison of Mean Deviation (MD) among Groups.}
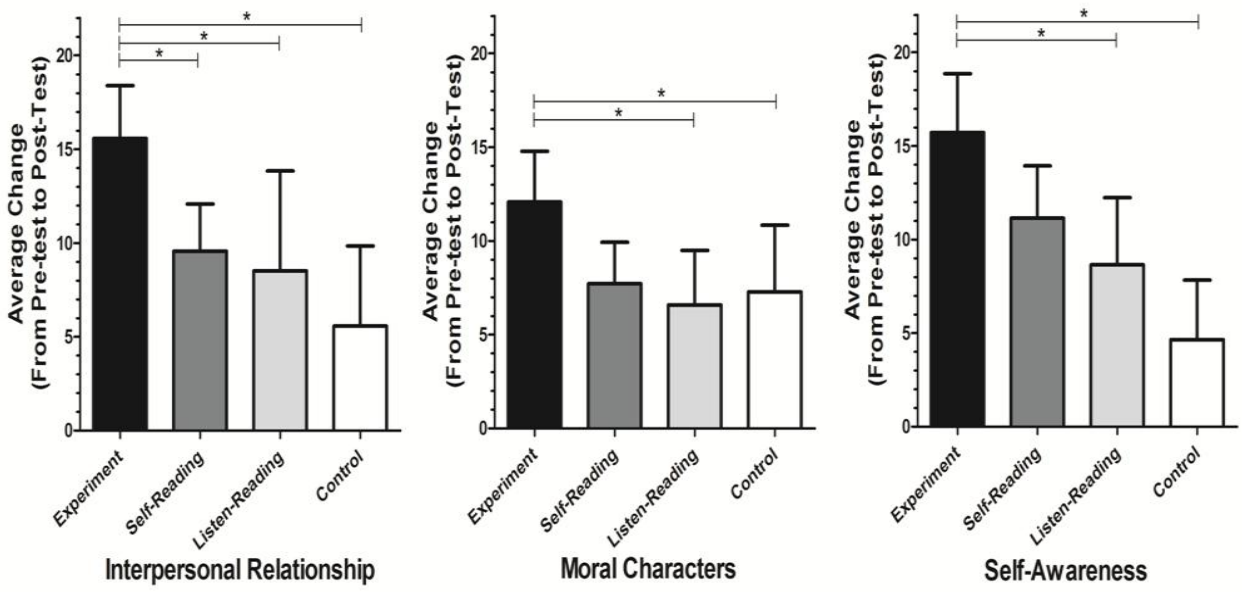

Note: *the result reached statistical significance.

reading of picture books plays a greater role in promoting children's social-emotional development.

Children's self-awareness reflects their understanding of the surrounding environment and their position in the society. It is an crucial prerequisite for socialization and personality improvement. Self-awareness affects children's social behavior and social adaptation (Wang, et al, 2011; Yang, 2014). Self-awareness is not innate. Instead, it is formed in the interactions with the objective social environment ( $\mathrm{Xu} \& \mathrm{Qu}, 2001)$. Children start to develop their awareness of social roles as well as their mind after their second year in kindergarten. In this study, through the activities of picture book reading, self-portrait, 'praise myself' and other mini games, children were guided to become aware of their similarities with and uniqueness from others. This was helpful for children to understand themselves properly and evaluate themselves positively. On the basis of proper self-evaluation, children could learn to evaluate others properly. In the process of answering thought invoking questions, children were free to deliver ideas so that they could fully express their thoughts, emotions and explanations. The participant children were also allowed to draw or act out their thoughts and feelings. In the activities within this study, children had a deeper self-experience, which enriched their inner world.

Rogers (1951) maintained that in social interactions, individuals require 'positive regard', and there is no exception for children. They also require recognition, attention and love from others. In the process of picture book reading, the investigators always responded to children with encouragement and positive words, so that the children could have a positive and new understanding of themselves. This process enabled chil- 
dren to be freed from self-centeredness. The participant children were able to recognize, comprehend, and adjust their emotions on the basis of their experiences in reading and game playing. They first mimicked the characters' actions of the story, and then learned to solve conflicts in constructive ways and manage interpersonal relationships.

\section{The Reasons Why the Game-Combined Guided Picture Book Reading Could Promote Social-Emotional Development.}

Why could game-combined guided picture book reading promote children's socialemotional development? We herein explained that the main reason is the scaffolding for positive construction in the reading activities, which involves the following four points:

First, children internalized many socialized experiences from reading picture books so that they were able to understand themselves and others, and then improve social skills. Nowadays, children's life experiences are mainly from their family, friends and people around them, but they were limited. However, picture books cover a wide range of contents, and through reading picture books, children could experience different lifestyles, meet a variety of people and things, and come across diverse views on life. Picture books served as a medium, and the game-combined reading activities enabled children to have a deeper experience and understanding of the materials in an enjoyable way. In such process, children could experience many that they cannot get in their real life. Their view horizons were expanded, their life experiences were enriched, and the knowledge and skills that they had learned could be transferred to their daily life (Guo, 2015). The social practice of games set up a certain life scenarios, in which children could understand simple social relations, and take initiative to solve problems (Fredrickson \& Marcial, 2005).

Second, game-combined guided reading of picture books adopted free and open discussion approaches, in which children were free to express their ideas and ask questions. This was to help children to learn the skills of thinking and reasoning. The improved ability of thinking in turn to help them understand the main points of the story and promote their cognitive and language development. Then, they may become intelligent people with better-developed emotions. In addition, the picture books use elaborate illustrations, simple words and emotional expressions, and depict the virtues of courage, confidence, optimism and kindness in the stories. These elements helped set role models for children to learn.

Third, the features of the three-dimensional design, full-scale demonstration and game participation enhanced participants' senses of experience. The gamecombined guided picture book reading enabled children to comprehend the content of stories, and further encouraged them to participate in the exploration and understanding of the external world through multiple forms of expression such as reading, acting, dancing, drawing, practicing, running and jumping. In the reading process, children gave many types of responses to the materials, such as dancing, clapping, acting and performing (Hickman, 1981). Game-combined guided picture book reading supported children to give responses to the stories, and encouraged investigators to interact with children. The embedded mini games in the reading process were not simply recreational 
activities. Instead, they incorporated higher level of meaning and value (Dewey, 2003). Children could use games to express their ideas, manage physical actions, express emotions and establish relationships with people and the environment. Game is the primary form and path of children's learning and development (Yang \& Li, 2009).

Fourth, the selected picture books contained rich social-emotional elements, and the themes were in accordance with preschool children's life experiences. Children, who have not yet developed strong observation abilities, might have egocentric consciousness, and therefore lack awareness, cognition and understanding of other's emotions and needs. This will lead to a lack of social-emotional skills such as helping others, cooperation, caring and compassion. The selected picture books contained a number of common emotions of children and themes such as empathy, self-esteem, self-reliance and self-awareness. The books were used to help children to develop their selfawareness (e.g., 'who I am' and 'how I am'), social skills (e.g., how to greet others, apologize, and share), the adaptability to a new environment, recognition of their own emotions, control of emotions, self-regulation abilities and pro-social behaviors (e.g., being willing to get along with peers, recognition of other's feelings and emotions and providing proper responses).

\section{Limitation}

Although the effects of game-combined guided picture book reading were significant in certain aspects, the duration of this study was relatively short. If longitudinal studies could be conducted among children, the durability of the guided reading effects could be investigated. This study only collected data from parents whose children participated in the study. The parents' evaluation was mainly based on their own life experiences with their own children. In future research, data should be collected from multiple sources (e.g., teachers, parents and children). The pre-test data were collected on a parents' meeting, while the post-tests were completed by the parents on their own at home. In both situations, parents' evaluation could be biased. If the methods of observation, interview and experiment could be involved, the evaluation of children's emotional development levels would be better-rounded. Meanwhile, some other study methods such as Social-Cognitive Aptitude Test and Object Cognition Test could be used.

Due to various objective limitations, this study only set up three experimental groups to compare game-combined guided picture book reading with traditional selfreading style and parent-reading-while-child-listening style. However, this study did not set up a game-only group (i.e., in this group, participants only play games without reading books). Therefore, we were not able to distinguish which was the fundamental influencing factor (i.e., the picture book reading, or game playing or the combination of both) on children' social emotional development. If game only groups could be added, the study results would be more rigorous and convincing.

\section{Conclusion}

- Picture book reading can promote children's social-emotional development. Furthermore, game-combined guided reading of picture books is more suitable 
for children's psychological characteristics, and its core mechanism is to promote children's scaffolding in learning and development. Therefore, if adults add mini games into the reading with children, it will not only enhance children's positive experience, but also support children's social-emotional development.

- Although this study has some limitations, the results indicate that gamecombined guided reading of picture books plays a role of positive construction in social-emotional development in children. This reading style is worth applying and promoting.

\section{Acknowledgement}

This study was supported by the Shanghai Philosophy and Social Science Planning Project (Grant No. 2017BSH004) and Shanghai Pujiang Program of China (Grant No. 12PJ037) to Juzhe Xi. We are immensely grateful to Dr. Xiaozhu Pan for her assistance with the translation of this article. Special thanks go to Dr. Edward Fox for his proofreading.

\section{References}

Aviles, A.M., Anderson, T.R., \& Davila, E.R. (2006). Child and adolescent socialemotional development within the context of school. Child Adoles Ment Hlth, 11(1), 3239.

Cao, Y.L. (2016). The understanding and practice of kindergarten curriculum through games. Stud Early Child Edu, 12, 61-63.

Chen, H.C. (1994). Characteristics, impact factors and measurement of children's social development - General report of "The social development of children aged 3-9 in China". Psychol Dev Edu, 4, 1-17.

Chen, J.F. (2008). Analysis on the problems and strategies on kindergarten-primary school transition in China. Forum Contem Edu, 11:54-55.

Chen, Y.X. (2017). Examination the practice of pleasing learning: Take a game-style elec- tronic picture book as an example. Taiwan Edu Rev, 9:311-313.

Cunningham, J.N., Kliewer, W., \& Garner, P.W. (2009). Emotion socialization, child emotion understanding and regulation, and adjustment in urban African American families: Differential associations across child gender. Dev Psypathol, 21(1):261-283.

Dewey, J. (2003). Democracy and Education. (Lin, Bao-shan translated) (pp.203-213). Taichung: Wu-Nan Book Company.

$\mathrm{Du}, \mathrm{M}$. (2015). The intervention study of picture books reading on the altruism behavior and social adjustment in rural primary school children. Unpublished Master's Dissertation, Jiangxi Normal University.

Duan, Y. (2010). The value of performance games for children's social development. Ability Wisdom, 35:259. 
Fang, W.P. (2012). The literature of play: Playfulness in children's literature. Stud Early Child Edu, 6:3-7.

Fei, L.L. (2016). Selection and application of picture books in kindergarten performance games. Pop Sci, 7:90.

Fredrickson, B.L., \& Losada, M.F. (2005). Positive affect and the complex dynamics of human flourishing. Am Psychol, 60(7):678-686.

Geng, M.L. (2010). Significance and educational suggestions in picture book reading for children's development. J Hunan Univ Sci Eng, 31(10):54-56.

Guo, Y.M. (2015). On the literature picture books for young children. Stud Early Child Edu, 8:64-66.

Harniss, M.K., Epstein, M.H., Ryser, G., \& Pearson, N. (1999). The behavioral and emotional rating scale: convergent validity. J Psy Edu Assess, 17(1):4-14.

He, M.Y., \& Liu, Y. (1999). Facing the 21st century, fostering children's playfulness. Stud Early Child Edu:20-23.

Hickman, J. (1981). A new perspective on response to literature: research in an elementary school setting. Res Teach Eng, 15(4):343-354.

Hsieh, S.H. (2004). The effect of the picture book guidance program on the social skills of elementary students. Unpublished Master's Dissertation, Normal University of Taipei.

Leng, X.Y. (2017). Analysis on the application of interesting picture book in the background of curriculum gamification. Read Write Period, 14(2):228.

Lian, G.L., Wang, H.S., Huang, X.N., Shi, S.H., Liu, G.Y., \& Zhang, J.R. (2008). Study on correlation between social-emotional development and behavior problems in 2-3 years old children. Chin J Child Hlth Care, 16(2):139-141+143.

Liu, S.W. (2004). An action research on using children's literature in teaching social studies. Unpublished Doctor's Dissertation, National Taiwan Normal University.

Liu, Y.X. (2010). On theoretical significance of children's social development. J College NW Adult Edu, 6:80-81+65.

Lv, X., \& Long, W. (2006). On Vygotsky's Play Theories. Stud Early Child Edu, 6:53-55.
Mendez, J.L., McDermott, P., \& Fantuzzo, J. (2002). Identifying and promoting social competence with African American preschool children: Developmental and contextual considerations. Psychol Sch, 39(1):111123.

Meng, Q.Y. (2014). The influence of independent games on children's social development. J Kaifeng Inst Educ, 34(9):226-227.

Meng, Z.L. (1989). Human emotion. (pp.393). Shanghai: Shanghai People's Publishing House.

Pahl, K.M., \& Barrett, P.M. (2007). The development of social-emotional competence in preschool-aged children: An introduction to the Fun FRIENDS Program. Aust J Guid Counsel, 17(1):81-90.

Peng, X.C. (2016). Analysis of the game characteristics of children's literature. J Shandong Agr Eng Univ, 33(8):185-186.

Peng, X.P. (2009). Traceability of educational activities in kindergarten. Stud Early Child Edu, 10:17-22.

Ran, N.Y. (1994). Self-awareness and social development of children aged 3-9. Psychol Dev Edu, 4:18-21+29.

Rogers, C. (1951). Client-centered therapy: Its current practice, implications and theory. London: Constable.

Shaffer, D.R., \& Kipp, K. (2013). Developmental psychology: Childhood and adolescence (9th). (pp.380-381). Wadsworth: Cengage Learning.

Shi, S.H. (1994). Establishment of the Chinese children's social development literature database (CCSD). Psychol Dev Edu, 4:64$67+26$.

Sun, Y. (2017). Goals and implementation of picture book games curriculum. Stud Early Child Edu, 2:64-66.

Wang, Y.W., Wang, Z.H., \& Liu, J.J. (2011). The development of self-conscious emotion understanding of primary school children and its relationship with prosocial behaviour and peer acceptance. Psychol Dev Edu, 1:65-70.

Xu, J.H., \& Qu, J. (2001). Cultivation of selfconsciousness of preschool children. Stud Early Child Edu, 4:63-65.

Yang, B.J. (2002). The effect of sports game on social character development of children and 
adolescence. Chin Sports Sci Tech, 38(6):58-60.

Yang, L.Z., \& Wu, W.J. (2001). Social development and education of preschool children. (pp.11-16). Dalian: Liaoning Normal University Press.

Yang, W.P., Lei, Y.L., Chen, K.C., \& Hong, X.M. (2014). The experimental research of teaching by using social theme picture story books to promote the development of preschool children's prosocial behaviors. J Edu Stud, 10(6):87-94.

Yang, X.P., \& Li, C.Y. (2009). Reflection on children's play from the perspective of cultural philosophy. Stud Early Child Edu, 10:17-22.
Yang, Y.F. (2014). Promote the social development of young children. Chin J Child Hlth Care, 22(3):225-227.

Yang, Y.J. (2015). Preparation of preschoolers emotional and social development level of assessment tools. Res Teach, 38(2):114-118.

Zhang, Z., \& Zeng, B. (2016). Experimental study on picture books to the formation of children's sociality. J Shaanxi Xueqian Norm Univ, 32(1):83-86.

Zhou, X. (1990). Games and social development of children. Psychol Dev Edu, 4:246-251.

Zuo, Z.H., Xi, J.Z., \& Shi, J. (2012). Ameliorating preschoolers' challenging behaviors through instructive picture books reading. Stud Early Child Edu, 6:29-35.

Received: 02 August 2019

Revised: 13 August 2019

Accepted: 09 September 2019

The Chinese version of this article has been published in J Capital Norm Univ (Soc Sci Ed) 2018; 243(4):167-174. The English version has been authorized for being publication in BECE by the author(s) and the Chinese journal.

席居哲, 周文颖, 左志宏. 整合游戏与绘本, 发展情绪社会性一游戏式绘本指导阅读促进幼 儿情绪社会性发展的实证研究. 首都师范大学学报, 2018; 243(4):167-174. 